\title{
The benzene metabolite para-benzoquinone is genotoxic in human, phorbol-12-acetate-13-myristate induced, peripheral blood mononuclear cells at low concentrations
}

\author{
Götz Alexander Westphal · Jürgen Bünger · \\ Nadine Lichey · Dirk Taeger · Angelika Mönnich • \\ Ernst Hallier
}

Received: 9 September 2008 / Accepted: 15 January 2009 / Published online: 11 February 2009

(C) Springer-Verlag 2009

\begin{abstract}
Benzene is one of the most prominent occupational and environmental pollutants. The substance is a proven human carcinogen that induces hematologic malignancies in humans, probably at even low doses. Yet knowledge of the mechanisms leading to benzene-induced carcinogenesis is still incomplete. Benzene itself is not genotoxic. The generation of carcinogenic metabolites involves the production of oxidized intermediates such as catechol, hydroquinone and para-benzoquinone ( $p$-BQ) in the liver. Further activation to the ultimate carcinogenic intermediates is most probably catalyzed by myeloperoxidase (MPO). Yet the products of the MPO pathway have not been identified. If an oxidized benzene metabolite such as $p-\mathrm{BQ}$ was actually the precursor for the ultimate
\end{abstract}

G. A. Westphal $(\bowtie) \cdot$ J. Bünger $\cdot$ D. Taeger

BGFA, Research Institute of Occupational Medicine,

German Social Accident Insurance, Ruhr-University Bochum,

Bürkle-de-la-Camp-Platz 1, 44789 Bochum, Germany

e-mail: westphal@bgfa.ruhr-uni-bochum.de

J. Bünger

e-mail: buenger@bgfa.ruhr-uni-bochum.de

D. Taeger

e-mail: taeger@bgfa.ruhr-uni-bochum.de

N. Lichey · A. Mönnich · E. Hallier

Department of Occupational and Social Health,

Georg-August-University Göttingen, Waldweg 37,

37073 Göttingen, Germany

N. Lichey

e-mail: nadine.lichey@web.de

A. Mönnich

e-mail: amoenni@gwdg.de

E. Hallier

e-mail: ehallie@gwdg.de carcinogenic benzene metabolite and further activation proceeds via MPO mediated reactions, it should be possible to activate $p$-BQ to a genotoxic compound in vitro. We tested this hypothesis with phorbol-12-acetate-13myristate (PMA) activated peripheral blood cells exposed to $p$ - $\mathrm{BQ}$, using the cytokinesis-block micronucleus test. Addition of $20-28 \mathrm{ng} / \mathrm{ml}$ PMA caused a significant increase of micronuclei at low and non-cytotoxic $p$-BQ concentrations between 0.04 and $0.2 \mu \mathrm{g} / \mathrm{ml} \quad(0.37$ $1.85 \mu \mathrm{M})$. Thus with PMA or $p$-BQ alone no reproducible elevation of micronuclei was seen up to toxic concentrations. PMA and $p$-BQ induce micronuclei when administered jointly. Our results add further support to the hypothesis that MPO is a key enzyme in the activation of benzene.

Keywords Benzene · para-Benzoquinone ·

Phorbol-12-acetate-13-myristate

\section{Introduction}

Benzene [CAS 71-43-2] is widely used as a solvent and an intermediate in chemical syntheses. In addition, occupational exposure occurs in oil refineries and coke oven plants. Environmental exposure is nearly exclusively caused by benzene contained in gasoline. Benzene is a proven human carcinogen probably even at low doses. Particular concern has been aroused by two independent studies that showed a possible contribution of environmental benzene exposure to childhood leukemia (Crosignani et al. 2004; Steffen et al. 2004). Furthermore, acute hematotoxicity in adults can occur at atmospheric concentrations below $1 \mathrm{ppm}$ benzene (Lan et al. 2004). Despite its outstanding importance as an ubiquitous, highly toxic 
pollutant, knowledge of the mechanisms of benzene toxicity is still incomplete. Although a variety of effects on bone marrow can be demonstrated it is not yet clear that which metabolites are most important in either benzene-induced aplastic anemia or leukemia. Benzene metabolism alone is insufficient to fully describe benzene toxicity. The impact of benzene metabolites on bone marrow cells must be fully explored to determine how benzene exposure can result in decreased viability or genetic toxicity to cells in the bone marrow (Snyder 2007). Moreover, the reason for the observed species differences in benzene toxicity between experimental animals and humans is unclear: whereas hematopoietic malignancies occur in humans, benzene produces a variety of tumors in rats and mice (Maltoni et al. 1985; National Toxicology Program 1986). Furthermore, it is disputed if benzene induces only leukemia in humans (Lamm et al. 2005; Seidler et al. 2007) or a broader spectrum of hematologic malignancies (Hayes et al. 1997; Mehlman 2004; Smith et al. 2007).

The answers for these open questions are strongly hampered by the complex and not yet fully clarified metabolism of benzene. Initially, benzene is oxidized to metabolites such as 1,2-benzenediol [CAS No. 120-80-9] (catechol), hydroquinone [CAS 123-31-9] and $p$-BQ [CAS 106-51-4] in the liver, primarily by cytochrome P450 2E1. Since benzene does not induce liver tumors and human exposure is predominantly associated with disorders of the hematopoietic system, it was concluded that myeloperoxidase (MPO) mediated reactions are involved in the generation of the ultimate carcinogenic metabolites (Hayes et al. 1997; Smith et al. 2007; Environmental Protection Agency USA 1998). Actually, benzene causes malignancies in experimental animals preferentially in peroxidase rich tissues (Maltoni et al. 1985; National Toxicology Program 1986).

Benzene-induced oxidative DNA damage is enhanced in PMA-stimulated cells in vitro and in LPS-treated animals (Tuo et al. 1999). Consequently it was proposed that "peroxidatic metabolism of benzene's phenolic metabolites may be responsible for the increased free radical activity and toxicity produced by benzene in bone marrow, and that free radicals contribute, at least in part, to the toxic and leukemogenic effects of benzene" (Subrahmanyam et al. 1991). However, direct evidence for MPO mediated generation of genotoxic metabolites does not exist and benzene adducts which were detected in humans and experimental animals could not be identified (Bechtold et al. 1992; Krewet et al. 1993; McDonald et al. 1994; Creek et al. 1997).

Human MPO is expressed at high levels in the bone marrow and in peripheral blood cells such as neutrophils and monocytes. The enzyme is stored in "large dense azurophil granules" (Bainton et al. 1971) and is released during host defence and inflammatory reactions, parallel to the genera- tion of $\mathrm{H}_{2} \mathrm{O}_{2}$ and $\mathrm{HOCl}$. MPO activation can be experimentally induced by PMA (phorbol-12-acetate-13-myristate) or LPS (bacterial lipopolysaccharide). MPO is proposed to play a major role in the generation of tissue damage caused by chronic inflammation (Winterbourn 2002). Reactions accompanying MPO activation are suggested to take part in the toxification of oxidizable substances (Winterbourn 2002; Trush 1984; Eastmond and Smith 1990) or may act as co-factor in chemical carcinogenesis (Coussens and Werb 2002).

Benzene is one of the few strong carcinogens that yield negative results in in vitro mutagenicity tests (Zarani et al. 1999), whereas genotoxic effects are observed in vivo (Tweats et al. 2007). In addition, genotoxicity of benzene metabolites such as hydroquinone, catechol and $p$-BQ is absent or weak at toxic concentrations (Ludewig et al. 1989; Yager et al. 1990; Lévay and Bodell 1992). This most probably reflects the inability of in vitro systems to model a complex metabolism and interactions of different metabolizing compartments.

However, if an intermediate such as $p$-BQ is actually the precursor for the ultimate carcinogenic benzene metabolite and further activation proceeds via MPO mediated reactions, it should be possible to activate $p$-BQ to a genotoxic compound in vitro. Since benzene exposure leads to clastogenic effects (Smith et al. 2007; Tough et al. 1970; Forni 1971; Picciano 1979; Popp et al. 1992; Tompa et al. 1994; Rothman et al. 1995, 1996; Smith et al. 1998; Zhang et al. 1998, 2005), micronuclei should be suitable endpoints to monitor such effects.

Treatment of HL-60 cells with $3 \mu \mathrm{M} p$-BQ caused a threefold reactive oxygen species (ROS) production, cell proliferation and prolonged phosphorylation of ERK1/2 proteins. Catalase or the MEK protein inhibitor PD98059 reduced cell recruitment into the S-phase and ERK1/2 protein phosphorylation. Thus, $p$-BQ is able to induce ROS and cell proliferation. This would theoretically enhance the vulnerability of the exposed cells (Ruiz-Ramos et al. 2005).

Therefore, we proposed that the combination of $p$-BQ and PMA might be especially effective to investigate $p$-BQ activation by PMA and investigated if $p$-BQ can be activated by MPO mediated reactions by using the cytokinesis-block micronucleus technique and PMA activated peripheral human blood mononuclear cells.

\section{Materials and methods}

The study was approved by the Ethics committee of the Medical Faculty of the Georg-August-University, Göttingen. Written informed consent was obtained from all participants. 


\section{Micronucleus test}

The cytokinesis-block micronucleus assay was carried out according to Fenech (1993) using primary human lymphocytes from three different donors (donor 1 was a 45 -year-old male smoker; donor 2 a 47-year-old female non-smoker and donor 3 a 38-year-old male non-smoker). Blood was collected by venipuncture in Sodium-heparin tubes (Sarstedt AG \& Co, Nümbrecht, Germany), diluted 1:1 in phosphate buffered saline (PBS) and separated by a FICOLL gradient (Biochrom KG, Berlin, Germany) for isolation of lymphocytes. Approximately $1.2 \times 10^{6}$ cells were seeded in $2.5 \mathrm{ml}$ RPMI medium each (ICN, Eschwege, Germany) supplemented with 5\% fetal calf serum (FCS) (Biochrom KG, Berlin, Germany). Lymphocytes were stimulated by adding $5 \mu \mathrm{g} / \mathrm{ml}$ phytohemagglutinin (Biochrom KG, Berlin, Germany) and cultivated at $37^{\circ} \mathrm{C}$, $100 \%$ humidity and $5 \% \mathrm{CO}_{2}$ for $70 \mathrm{~h}$. PMA and $p$-BQ were added simultaneously 24 after having started the cultures. Cell division was blocked $44 \mathrm{~h}$ after starting the cultures by adding $4.5 \mu \mathrm{g} / \mathrm{ml}$ cytochalasin-B (SigmaAldrich, Steinheim, Germany).

Without addition of PMA, up to $5 \mu \mathrm{g} / \mathrm{ml} p$-BQ (minimum 97\% purity, Sigma-Aldrich, Steinheim, Germany) were applied to the cultures $(2.5 \mathrm{ml})$. Co-incubation with PMA was initially done using 24-80 ng PMA and up to $1 \mu \mathrm{g} / \mathrm{ml} p$-BQ. PMA was processed as follows: PMA was dissolved in DMSO $(1 \mathrm{mg} / \mathrm{ml})$ and stored in $10 \mu \mathrm{l}$ aliquots at $-18^{\circ} \mathrm{C}$. Prior to the addition to the cultures PMA was mixed with $990 \mu \mathrm{l}$ medium. Mitomycin C (Sigma-Aldrich) served as positive control. One sample without addition of $p$-BQ and PMA served as negative control as did another sample with addition of PMA only.

Lymphocytes were sampled $68 \mathrm{~h}$ after having started the cultures and $28 \mathrm{~h}$ after addition of cytochalasin-B by centrifugation for $5 \mathrm{~min}$ at $175 \times \mathrm{g}$ and $20^{\circ} \mathrm{C}$. Hypotonic treatment was performed by careful resuspension of the cells in $5 \mathrm{ml}$ hypotonic saline $(0.07 \mathrm{M} \mathrm{KCl} / 0.15 \mathrm{M} \mathrm{NaCl})$. Cells were collected for $5 \mathrm{~min}$ at $175 \times g$ and $20^{\circ} \mathrm{C}$ immediately after the addition of hypotonic solution. The cell pellet was resuspended in $3 \mathrm{ml}$ ice cold methanol/acetic acid (4:1). Cell fixation was performed twice. Finally the cells were pelleted for 5 min at $4^{\circ} \mathrm{C}$ and $175 \times g$ and transferred onto ice cold degreased slides. The slides were randomized and subsequently stained with 3\% Giemsa R66 'Gurr' (BDH, Promochem $\mathrm{GmbH}$, Wesel, Germany) for $7 \mathrm{~min}$.

Six independent experiments were performed for donor 1 and four experiments each for donors 2 and 3. For each experiment blood was freshly collected and each single experiment was done on a different date. At least five concentrations were examined. Cell viability was determined by trypan blue exclusion test (Merck, Darmstadt, Germany) and additionally by evaluation of the nuclear division index
(NDI, Eastmond and Tucker 1989). Cell scoring was done according to the criteria outlined by Fenech (1993). Binucleated cells and cells not containing more than four micronuclei with preserved cytoplasm were counted.

Additional acceptance criteria for a genotoxic effect were: positive- and solvent control within the historical range, significantly elevated frequency of micronuclei exceeding the respective control $(0 \mu \mathrm{g} / \mathrm{ml} p$-BQ with or without PMA) at non-toxic concentrations and unchanged $\mathrm{pH}$. More than one succeeding concentration yielding total cell counts below 1,000 binucleated cells, a NDI $<1.4$ and viability below $60 \%$ were regarded as toxic.

\section{Statistics}

The micronucleus rates of selected experiments were compared to the rates of negative controls with PMA and without $p-\mathrm{BQ}$, and additionally to the rates of negative controls without PMA and without $p$-BQ using Fisher's exact test. The Cochrane-Armitage test was applied to selected dose samples to test positive trends. SAS 9.2 software was used for all calculations (SAS Institute Inc, Cary, NC).

\section{Results}

The concentration range for the tests was initially determined using between 24 and $80 \mathrm{ng} / \mathrm{ml}$ PMA in combination with up to $8.0 \mu \mathrm{g} / \mathrm{ml} p$-BQ. At and above $32 \mathrm{ng} / \mathrm{ml}$ PMA (70 ng/2.5 ml medium) toxicity and strong variations of the effects occurred (data not shown). In single concentration range finding experiments PMA concentrations at and above $32 \mathrm{ng} / \mathrm{ml}$ caused a significant increase of micronuclei (example shown in Table 1, experiment 2). However, these effects were poorly reproducible and most probably attributable to toxicity.

In some concentration range finding experiments significantly elevated micronuclei counts occurred with addition of $p$-BQ alone at and above $4 \mu \mathrm{g} / \mathrm{ml}$ (example shown in Table 1, experiment 11). Yet these effects were as well poorly reproducible and attributable to toxicity.

In single concentration range finding experiments in which PMA concentrations at and above $32 \mathrm{ng} / \mathrm{ml}$ were used, elevation of micronuclei showed a bimodal distribution. This appeared without noticeable effects on the NDI. In case of bimodal distribution of elevated micronuclei, the second elevation occurred at about $60 \%$ cytotoxicity (example shown in Table 1, experiments 1 and 2). In another set of experiments weak PMA genotoxicity occurred and the combination with $p$-BQ yielded a strong synergistic elevation of micronuclei.

With the aim to improve reproducibility, we performed a more detailed analysis of the $p$-BQ concentration range 
Table 1 Toxic effects of para-benzoquinone in the in vitro micronucleus test

\begin{tabular}{|c|c|c|c|c|c|c|c|c|}
\hline Exp. no. & PMA (ng/ml) & $p$-BQ $(\mu \mathrm{g} / \mathrm{ml})$ & NDI & Viability (\%) & $\mathrm{MN}$ & $P$ & $P^{*}$ & $P^{* *}$ \\
\hline \multicolumn{9}{|l|}{ Donor 1} \\
\hline \multirow[t]{9}{*}{1} & 0 & 0 & 1.53 & 98 & 2 & & & \\
\hline & 0 & 2.5 & 1.41 & 40 & 2 & & & \\
\hline & 0 & 5 & 1.21 & 40 & Tox & & & \\
\hline & 32 & 0 & 1.62 & 80 & 1 & & & \\
\hline & 32 & 0.05 & $\mathrm{NE}$ & 80 & $\mathrm{NE}$ & & & \\
\hline & 32 & 0.2 & 1.62 & 80 & 9 & & 0.0212 & \\
\hline & 32 & 0.3 & 1.76 & 60 & 2 & & & \\
\hline & 32 & 0.4 & 1.49 & 60 & 12 & & 0.0033 & 0.0126 \\
\hline & 32 & 0.5 & 1.67 & 60 & 1 & & & \\
\hline \multirow[t]{9}{*}{2} & 0 & 0 & 1.75 & 90 & 1 & & & \\
\hline & 0 & 2 & 1.59 & 80 & 1 & & & \\
\hline & 0 & 4 & 1.45 & 40 & 1 & & & \\
\hline & 32 & 0 & 1.62 & 80 & 18 & & & $<0.0001$ \\
\hline & 32 & 0.04 & 1.63 & 80 & 9 & & & 0.0212 \\
\hline & 32 & 0.08 & 1.56 & 60 & 30 & & & $<0.0001$ \\
\hline & 32 & 0.12 & 1.45 & 60 & 28 & & & $<0.0001$ \\
\hline & 32 & 0.16 & 1.64 & 60 & 12 & & & 0.0033 \\
\hline & 32 & 0.20 & 1.55 & 60 & 24 & & & $<0.0001$ \\
\hline \multirow[t]{9}{*}{3} & 0 & 0 & 1.79 & 90 & 1 & & & \\
\hline & 0 & 2 & 1.63 & 90 & 1 & & & \\
\hline & 0 & 4 & Tox & 60 & Tox & & & \\
\hline & 32 & 0 & 1.55 & 90 & 1 & & & \\
\hline & 32 & 0.04 & 1.57 & 90 & 2 & & & \\
\hline & 32 & 0.08 & 1.55 & 80 & 1 & & & \\
\hline & 32 & 0.12 & 1.48 & 80 & 14 & & 0.0009 & 0.0009 \\
\hline & 32 & 0.16 & 1.60 & 70 & 6 & & & \\
\hline & 32 & 0.20 & $\mathrm{NE}$ & 70 & NE & & & \\
\hline \multirow[t]{9}{*}{4} & 0 & 0 & 1.73 & 98 & 1 & & & \\
\hline & 0 & 4 & Tox & 40 & Tox & & & \\
\hline & 0 & 8 & Tox & 20 & Tox & & & \\
\hline & 28 & 0 & 1.51 & 80 & 2 & & & \\
\hline & 28 & 0.1 & 1.60 & 80 & 1 & & & \\
\hline & 28 & 0.2 & 1.44 & 80 & 10 & & 0.0380 & 0.0115 \\
\hline & 28 & 0.3 & 1.56 & 70 & 1 & & & \\
\hline & 28 & 0.4 & 1.61 & 60 & 2 & & & \\
\hline & 28 & 0.5 & 1.64 & 60 & 2 & & & \\
\hline \multirow[t]{9}{*}{5} & 0 & 0 & 1.75 & 98 & 1 & & & \\
\hline & 0 & 2 & 1.68 & 80 & 3 & & & \\
\hline & 0 & 4 & 1.51 & 70 & 1 & & & \\
\hline & 28 & 0 & 1.70 & 80 & 2 & & & \\
\hline & 28 & 0.04 & 1.68 & 80 & 3 & & & \\
\hline & 28 & 0.08 & 1.70 & 70 & 1 & & & \\
\hline & 28 & 0.12 & 1.65 & 70 & 20 & & 0.0001 & $<0.0001$ \\
\hline & 28 & 0.16 & 1.68 & 70 & 20 & & 0.0001 & $<0.0001$ \\
\hline & 28 & 0.20 & 1.67 & 70 & 12 & & 0.0126 & 0.0033 \\
\hline
\end{tabular}


Table 1 continued

\begin{tabular}{|c|c|c|c|c|c|c|c|c|}
\hline Exp. no. & PMA (ng/ml) & $p$-BQ $(\mu \mathrm{g} / \mathrm{ml})$ & NDI & Viability (\%) & MN & $P$ & $P^{*}$ & $P^{* *}$ \\
\hline \multirow[t]{9}{*}{6} & 0 & 0 & 1.6 & 95 & 3 & & & \\
\hline & 0 & 2 & 1.46 & 80 & 2 & & & \\
\hline & 0 & 4 & 1.30 & 60 & 2 & & & \\
\hline & 24 & 0 & 1.50 & 80 & 1 & & & \\
\hline & 24 & 0.04 & 1.47 & 80 & 18 & & $<0.0001$ & 0.0014 \\
\hline & 24 & 0.08 & 1.39 & 80 & 4 & & & \\
\hline & 24 & 0.12 & 1.41 & 80 & 12 & & 0.0033 & 0.0345 \\
\hline & 24 & 0.16 & 1.41 & 80 & 12 & & 0.0033 & 0.0345 \\
\hline & 24 & 0.20 & 1.28 & 80 & 3 & & & \\
\hline
\end{tabular}

Positive control: $0.08-0.1 \mu \mathrm{mol} / \mathrm{ml}$ mitomycin induced $11-21 \mathrm{MN}$

Donor 2

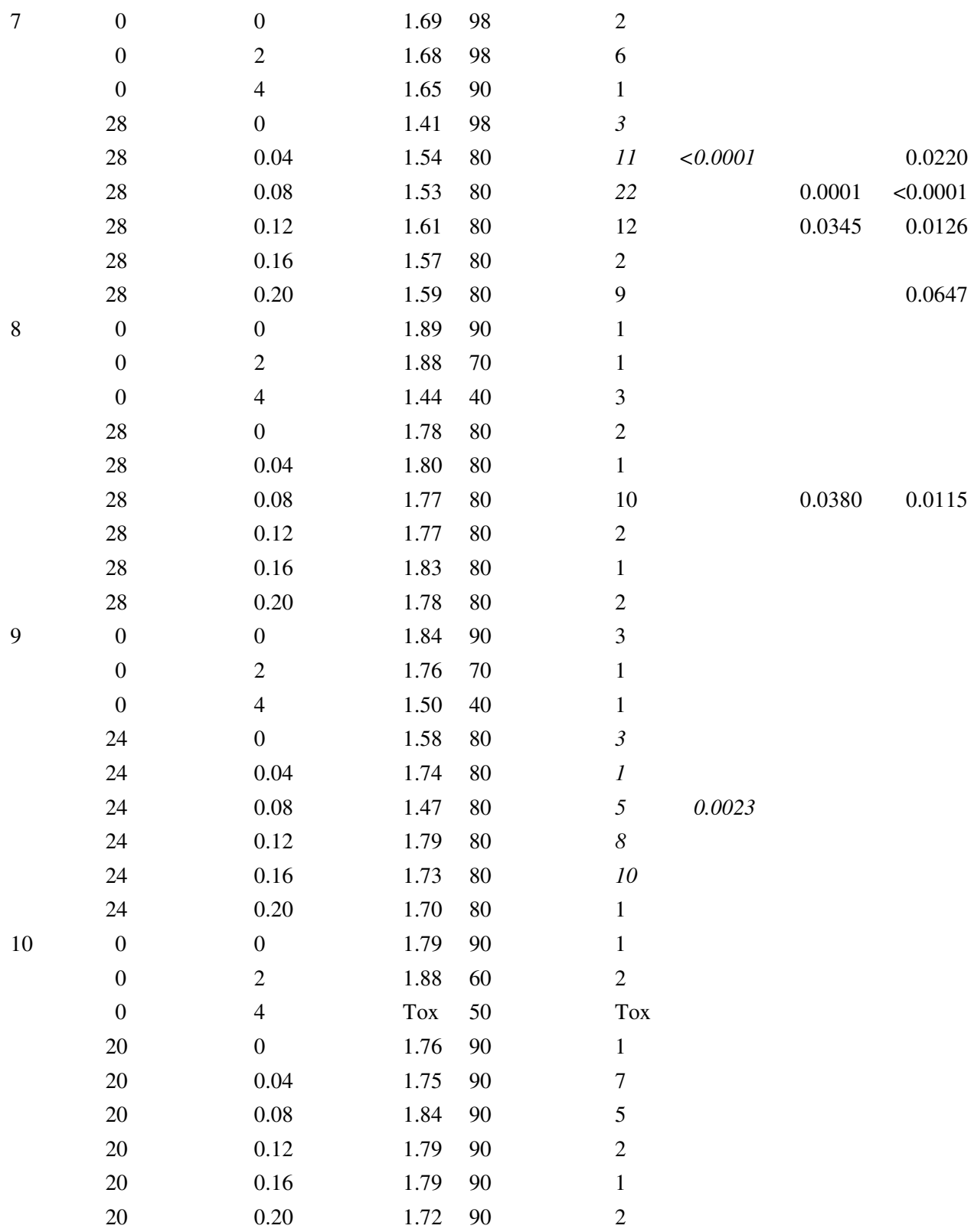

Positive control: $0.08-0.1 \mu \mathrm{mol} / \mathrm{ml}$ mitomycin induced $11-27 \mathrm{MN}$ 
Table 1 continued

Results from the in vitro micronucleus test using isolated lymphocytes from three different donors. Results of 14 independent experiments are displayed.

$P M A$ Phorbol-12-acetat-13myristat, $p-B Q$ para-benzoquinone, $N D I$ nuclear division index, $M I$ mitotic index, $M N$ micronuclei, $N E$ not evaluable, to $x$ toxic, $P$ one-sided $P$ value of Cochran-Armitage trend test (experiments shown in italics), $P^{*}$ two-sided $P$ value of Fisher's exact test based on the corresponding controls with PMA and without $p-\mathrm{BQ}, P^{* *}$ twosided $P$ value of Fisher's exact test based on the samples without PMA and without $p$-BQ

\begin{tabular}{|c|c|c|c|c|c|c|c|c|}
\hline Exp. no. & PMA (ng/ml) & $p$-BQ $(\mu \mathrm{g} / \mathrm{ml})$ & NDI & Viability (\%) & $\mathrm{MN}$ & $P$ & $P^{*}$ & $P^{* *}$ \\
\hline \multicolumn{9}{|l|}{ Donor 3} \\
\hline \multirow[t]{9}{*}{11} & 0 & 0 & 1.84 & 95 & 1 & & & \\
\hline & 0 & 2 & 1.75 & 50 & 3 & & & \\
\hline & 0 & 4 & 1.63 & 40 & 8 & & 0.0386 & \\
\hline & 24 & 0 & 1.48 & 80 & 3 & & & \\
\hline & 24 & 0.04 & 1.58 & 80 & 16 & & 0.0042 & 0.0003 \\
\hline & 24 & 0.08 & 1.41 & 90 & 12 & & 0.0345 & 0.0033 \\
\hline & 24 & 0.12 & 1.58 & 80 & 12 & & 0.0345 & 0.0033 \\
\hline & 24 & 0.16 & 1.52 & 80 & 2 & & & \\
\hline & 24 & 0.20 & 1.59 & 80 & 1 & & & \\
\hline \multirow[t]{9}{*}{12} & 0 & 0 & 1.87 & 99 & 1 & & & \\
\hline & 0 & 2 & Tox & 60 & Tox & & & \\
\hline & 0 & 4 & Tox & 40 & Tox & & & \\
\hline & 24 & 0 & 1.32 & 90 & 5 & & & \\
\hline & 24 & 0.02 & 1.57 & 90 & 9 & 0.0229 & 0.4223 & \\
\hline & 24 & 0.03 & 1.53 & 90 & 14 & & 0.0623 & \\
\hline & 24 & 0.04 & 1.48 & 90 & 13 & & 0.0948 & \\
\hline & 24 & 0.08 & 1.43 & 90 & 2 & & & \\
\hline & 24 & 0.12 & $\mathrm{NE}$ & $\mathrm{NE}$ & $\mathrm{NE}$ & & & \\
\hline \multirow[t]{9}{*}{13} & 0 & 0 & 1.87 & 90 & 1 & & & \\
\hline & 0 & 1 & 1.75 & 80 & 5 & & & \\
\hline & 0 & 2 & Tox & 60 & Tox & & & \\
\hline & 20 & 0 & 1.42 & 90 & 1 & & & \\
\hline & 20 & 0.02 & 1.54 & 90 & 4 & & & \\
\hline & 20 & 0.04 & 1.68 & 90 & 4 & & & \\
\hline & 20 & 0.08 & 1.62 & 85 & 3 & & & \\
\hline & 20 & 0.12 & 1.55 & 80 & 7 & & & \\
\hline & 20 & 0.16 & 1.55 & 80 & 4 & & & \\
\hline \multirow[t]{9}{*}{14} & 0 & 0 & 1.80 & 90 & 1 & & & \\
\hline & 0 & 1 & Tox & 80 & Tox & & & \\
\hline & 0 & 2 & Tox & 50 & Tox & & & \\
\hline & 20 & 0 & 1.59 & 90 & 1 & & & \\
\hline & 20 & 0.02 & 1.47 & 90 & 4 & 0.0473 & & \\
\hline & 20 & 0.04 & 1.50 & 90 & 6 & & & \\
\hline & 20 & 0.08 & 1.51 & 90 & 2 & & & \\
\hline & 20 & 0.12 & 1.46 & 80 & 5 & & & \\
\hline & 20 & 0.16 & 1.45 & 80 & 1 & & & \\
\hline
\end{tabular}

Positive control: $0.08-0.1 \mu \mathrm{mol} / \mathrm{ml}$ mitomycin induced $12-20 \mathrm{MN}$ by applying $20-28 \mathrm{ng} / \mathrm{ml}(0.37-1.85 \mu \mathrm{M})$ PMA. Under these conditions, a significant increase of micronuclei occurred between 0.04 and $0.2 \mu \mathrm{g} p$-BQ: In 4 out of 11 experiments using 20-28 $\mathrm{ng} / \mathrm{ml}$ PMA, significance was reached in terms of a positive trend test (experiments 7, 9, 12 and 14). In six experiments (experiments 1, 3, 4, 5, 6 and 8) at least one concentration yielded a significant elevation of micronuclei compared to the control with addition of PMA. In two experiments (experiments 7 and 12) significant elevated micronuclei occurred in combination with a positive trend test and in two experiments with addition of $20 \mathrm{ng} / \mathrm{ml}$ PMA neither a positive trend test nor a significant elevation was seen (experiments 10 and 13). Viability-according to the trypane exclusion test-constituted $70-90 \%$ and only minor changes in the NDI were seen (Table 1). 


\section{Discussion}

Central questions concerning benzene toxicity are still unanswered: why is benzene such a potent carcinogen whereas compounds with a similar chemical structure such as phenol, hydroquinone or $p$-BQ are not (although they are metabolites of benzene)? Does benzene cause the formation of mutagenic DNA-adducts or rather act by a clastogenic effect? Why are only hematopoietic malignancies seen in humans whereas a broader tumor spectrum occurs in experimental animals? Are only myeloic stem cells targets of benzene toxicity in humans? Since no convincing evidence for genotoxic effects of $p$-BQ, phenol, 1,2-benzenediol or hydroquinone exists, do other benzene metabolites contribute to benzene carcinogenicity instead? An appropriate in vitro system could help to answer these open questions.

We observed a significant elevation of micronuclei at very low, non-cytotoxic concentrations between 0.04 and $0.2 \mu \mathrm{g} / \mathrm{ml} p$-BQ using PMA activated peripheral blood cells. This is the first report that shows genotoxic effects of $p$-BQ in peripheral blood cells at non-toxic concentrations and the first direct evidence for in vitro activation of a benzene metabolite by PMA inducible reactions. Notably, we achieved positive results at very low $p$-BQ concentrations between 0.37 and $1.85 \mu \mathrm{M}$, whereas in formerly published investigations $p$-BQ alone induced an elevation of micronuclei only at toxic concentrations above $35 \mu \mathrm{M}$ in V79 cells (Ludewig et al. 1989) and at and above $2.5 \mu \mathrm{M}$ in human lymphocytes (Yager et al. 1990). Treatment of HL-60 cells with cytotoxic concentrations of $500 \mu \mathrm{M}$ hydroquinone and $250 \mu \mathrm{M} 1,2,4$,-benzenetriole resulted in the formation of a single DNA adduct in HL-60 cells which was detected by ${ }^{32} \mathrm{P}$-postlabelling. We could not reproduce former positive results using the cytokinesis-block micronucleus technique, human lymphocytes and up to $46.3 \mu \mathrm{M} p$-BQ without addition of PMA. Only addition of PMA at relatively low concentrations resulted in reproducible $p$-BQ genotoxicity. These effects occurred at a narrow concentration range between 20 and $28 \mathrm{ng}$ PMA. Toxicity at and above $32 \mathrm{ng} / \mathrm{ml}$ PMA masked genotoxic effects of $p$-BQ; whereas addition of less than $24 \mathrm{ng} / \mathrm{ml}$ PMA yielded only weak effects.

Cytotoxic artifacts are often misinterpreted as genotoxic effects when using in vitro assays and eukaryotic cells (Kirkland et al. 2007). The in vitro micronucleus test however allows the parallel investigation of the nuclear division index or the mitotic index to monitor cytotoxicity, and evaluation of binucleated (vital) cells can avoid the inclusion of damaged cells (Fenech 1993). Admittedly in our experiments concentrations at and above $32 \mathrm{ng} / \mathrm{ml}$ PMA yielded inconclusive results and poor reproducibility, even at concentrations which did not appreciably affect the NDI. Some of these experiments showed a bimodal elevation of micronuclei, first between $0.04-0.2 \mu \mathrm{g} / \mathrm{ml} p$-BQ and $28-32 \mathrm{ng} / \mathrm{ml}$
PMA; second at and above $0.4 \mu \mathrm{g} / \mathrm{ml} p$-BQ and, according to the typane blue exclusion test, at about $60 \%$ cytotoxicity (Table 1). This second elevation might be caused by cytotoxic artefacts.

Acceptance criteria for a positive in vitro micronucleus test are not consistently used. A previous publication of the "Gesellschaft für Umwelt-Mutationsforschung" defined a dose-effect relationship as follows: if there were at least two consecutive concentrations having increased aberration frequencies and the effect of the higher concentration was more pronounced than that of the lower, this was regarded as dose-effect relationship. A doubling over control was not necessarily considered adequate by itself (Miller et al. 1998). According to a more recent publication a doserelated increase in micronuclei frequencies (e.g. trend test) which exceeds statistically significantly the upper limit of the historical and concurrent negative control (chi-square or Fisher's exact test) or at least a twofold increase over mean control micronuclei frequencies are required for a positive call. If a chemical meets all these criteria, it is proposed to be considered clearly positive. If a chemical satisfies none of these criteria, it should be considered clearly negative (Corvi et al. 2008).

In 2 out of 11 of our experiments in which 20 and $28 \mathrm{ng} / \mathrm{ml}$ PMA were applied, we achieved a significant doseresponse according to the Cochrane-Armitage test and a statistically significant deviation from the concurrent negative control according to the Fisher's exact test. Two experiments were clearly negative, in both we had applied $20 \mathrm{ng} /$ ml PMA. Accordingly the minimal effective PMA dose concerning $p$-BQ activation was between 20 and $24 \mathrm{ng} / \mathrm{ml}$ PMA. The remaining experiments showed a significant elevation according to a positive trend test or a positive Fisher's exact test.

The concentration range for a genotoxic effect is very narrow, most probably because the dose-response could be influenced by cytotoxic effects of both PMA and $p$-BQ. In addition, the concentration range can vary from donor to donor and test to test because the amount of inducible cells may be different and the PMA response may be modified by genetic- or life style factors. In fact, donor 1 showed the strongest variations in the results and a dose-response relationship could not be established. Interestingly donor 1 was the only smoker. However, we did not systematically evaluate a possible smoking effect on the results.

Phorbol-12-acetate-13-myristate induced peripheral blood cells are routinely used as a model for the investigation of inflammation and might enable the investigation of the role of inflammation in chemically induced carcinogenesis (Eastmond and Smith 1990). PMA induces oxidative bursts (Walrand et al. 2003) and oxidative DNA damage (Dzarlieva-Petrusevska and Füsenig 1985; Petrusevska et al. 1988). An influence of PMA on the generation of 
benzene-induced oxidative DNA damage in rats was shown (Subrahmanyam et al. 1991). Toxic effects of PMA are mediated by MPO induction. MPO and other peroxidases catalyze the generation of hypochloric acid from $\mathrm{H}_{2} \mathrm{O}_{2}$ and $\mathrm{Cl}^{-}$(Aucherè and Capeillère-Blandin 1999), reactions of phenolic compounds (Eastmond et al. 1986) and 1,2-benzenediol to highly reactive intermediates. The binding of 1,2-benzenediol peroxidation products to $\mathrm{N}-7$ guanine and $N-3$ adenine results in DNA depurination (Cavalieri et al. 2002). Accordingly, benzene-induced oxidative DNA damage is enhanced in PMA-stimulated cells in vitro and in LPS-treated animals (Tuo et al. 1999). Altogether evidence points towards peroxidase mediated benzene toxicity.

Physiologically MPO is released during host defence and inflammatory reactions, parallel to the generation of $\mathrm{H}_{2} \mathrm{O}_{2}$. The enzyme was proposed to be involved in the generation of tissue damage caused by chronic inflammation (Winterbourn 2002). Reactions accompanying MPO activation were suggested to take part in the toxification of oxygen reactive substances (Winterbourn 2002; Trush 1984; Eastmond and Smith 1990) or to act as co-factor in chemical carcinogenesis (Coussens and Werb 2002). Activation of $p$-BQ via PMA-induced reactions which is shown in our experiments, may provide an experimental approach to test this hypothesis in vitro. Furthermore our results will enable the comparative investigation of other benzene metabolites such as HQ or catechol.

In conclusion, $p$-BQ can be activated to genotoxic intermediates when administered jointly with PMA. Our results confirm the hypothesis that MPO is a key enzyme in the activation of benzene.

\section{References}

Aucherè F, Capeillère-Blandin C (1999) NADPH as a co-substrate for studies of the chlorinating activity of myeloperoxidase. Biochem J 343:603-613

Bainton DF, Ullyotm JL, Farquhar MG (1971) The development of neutrophilic polymorphonuclear leukocytes in human bone marrow. J Exp Med 134:907-934

Bechtold WE, Willis JK, Sun JD, Griffith WC, Reddy TV (1992) Biological markers of exposure to benzene: $S$-phenylcysteine in albumin. Carcinogenesis 13:1217-1220

Cavalieri EL, Li KM, Balu N, Saeed M, Devanesan P, Higginbotham S, Zhao J, Gross ML, Rogan EG (2002) Catechol ortho-quinones: the electrophilic compounds that form depurinating DNA adducts and could initiate cancer and other diseases. Carcinogenesis 23:1071-1077

Corvi R, Albertini S, Hartung T, Hoffmann S, Maurici D, Pfuhler S, van Benthem J, Vanparys P (2008) ECVAM retrospective validation of in vitro micronucleus test (MNT). Mutagenesis 23:271-283

Coussens LM, Werb Z (2002) Inflammation and cancer. Nature 420:860-867

Creek MR, Mani C, Vogel JS, Turteltaub KW (1997) Tissue distribution and macromolecular binding of extreme low doses of $\left[{ }^{14} \mathrm{C}\right]-$ Benzene in B6C3F1 mice. Carcinogenesis 18:2421-2427
Crosignani P, Tittarelli A, Borgini A, Codazzi T, Rovelli A, Porro E, Contiero P, Bianchi N, Tagliabue G, Fissi R, Rossitto F, Berrino F (2004) Childhood leukemia and road traffic: a population-based case-control study. Int J Cancer 108:596-599

Dzarlieva-Petrusevska RT, Füsenig NE (1985) Tumor promoter 12-Otetradecanoylphorbol-13-acetate (TPA)-induced chromosome aberrations in mouse keratinocyte cell lines: a possible genetic mechanism of tumor promotion. Carcinogenesis 6:1447-1456

Eastmond DA, Tucker JD (1989) Identification of aneuploidy-inducing agents using cytokinesis-blocked human lymphocytes and an antikinetochore antibody. Environ Mol Mutagen 13:34-43

Eastmond DA, Smith MT (1990) Xenobiotic activation by stimulated human polymorphonuclear leukocytes and myeloperoxidase. Methods Enzymol 186:579-585

Eastmond DA, Smith MT, Ruzo LO, Ross D (1986) Metabolic activation of phenol by human myeloperoxidase and horseradish peroxidase. Mol Pharmacol 30:674-679

Environmental Protection Agency USA (1998) Carcinogenic effects of benzene: an update. EPA document 600/P-97/001. National Center for Environmental Assessment, Washington Office, Office of Research and Development, US Environmental Protection Agency

Fenech M (1993) The cytokinesis-block micronucleus technique: a detailed description of the method and its application to genotoxicity studies in human populations. Mutat Res 285:35-44

Forni A (1971) Chromosome studies in workers exposed to benzene or toluene or both. Arch Environ Health 22:373-378

Hayes RB, Yin SN, Dosemeci M, Li GL, Wacholder S, Travis LB, Li CY, Rothman N, Hoover RN, Linet MS (1997) Benzene and the dose-related incidence of hematologic neoplasms in China. J Natl Cancer Inst 89:1065-1071

Kirkland D, Pfuhler S, Tweats D, Aardema M, Corvi R, Darroudi F, Elhajouji A, Glatt H, Hastwell P, Hayashi M, Kasper P, Kirchner S, Lynch A, Marzin D, Maurici D, Meunier JR, Muller L, Nohynek G, Parry J, Parry E, Thybaud V, Tice R, van Benthem J, Vanparys P, White P (2007) How to reduce false positive results when undertaking in vitro genotoxicity testing and thus avoid unnecessary follow-up animal tests: report of an ECVAM Workshop. Mutat Res 628:31-55

Krewet E, Verkoyen C, Müller G, Schell C, Popp W, Norpoth K (1993) Studies on guanine adducts excreted in rat urine after benzene exposure. Carcinogenesis 14:245-250

Lamm SH, Engel A, Byrd DM (2005) Non-Hodgkin lymphoma and benzene exposure: a systematic literature review. Chem Biol Interact 153-154:231-237

Lan Q, Zhang L, Li G, Vermeulen R, Weinberg RS, Dosemeci M, Rappaport SM, Shen M, Alter BP, Wu Y, Kopp W, Waidyanatha S, Rabkin C, Guo W, Chanock S, Hayes RB, Linet M, Kim S, Yin S, Rothman N, Smith MT (2004) Hematotoxicity in workers exposed to low levels of benzene. Science 306:1774-1776

Lévay G, Bodell WJ (1992) Potentiation of DNA adduct formation in HL-60 cells by combinations of benzene metabolites. Proc Natl Acad Sci USA 89:7105-7109

Ludewig G, Dogra S, Glatt H (1989) Genotoxicity of 1, 4-benzoquinone and 1, 4-naphthoquinone in relation to effects on glutathione and $\mathrm{NAD}(\mathrm{P}) \mathrm{H}$ levels in V79 cells. Environ Health Perspect $82: 223-228$

Maltoni C, Conti B, Cotti G, Belpoggi F (1985) Experimental studies on benzene carcinogenicity at the Bologna Institute of Oncology: current results and ongoing research. Am J Ind Med 7:415-446

McDonald TA, Yeowell-O'Connell K, Rappaport SM (1994) Comparison of protein adducts of benzene oxide with benzoquinone in the blood and bone marrow of rats and mice exposed to $\left[{ }^{14} \mathrm{C} /\right.$ ${ }^{13}$ C6]benzene. Cancer Res 54:4907-4914

Mehlman MA (2004) Benzene: a haematopoietic and multi-organ carcinogen at any level above zero. Eur J Oncol 9:15-36 
Miller B, Pötter-Locher F, Seelbach A, Stopper H, Utesch D, Madle S (1998) Evaluation of the in vitro micronucleus test as an alternative to the in vitro chromosomal aberration assay: position of the GUM Working Group on the in vitro micronucleus test. Gesellschaft für Umwelt-Mutations-forschung. Mutat Res 410:81-116

National Toxicology Program (1986) Toxicology and Carcinogenesis Studies of Benzene (CAS No. 71-43-2) in F344/N Rats and B6C3F $_{1}$ Mice (Gavage Studies), NTP Technical Report 289, NIH Publ. No. 86-2545, Research Triangle Park, NC

Petrusevska RT, Fürstenberger G, Marks F, Füsenig NE (1988) Cytogenetic effects caused by phorbol ester tumor promoters in primary mouse keratinocyte cultures: correlation with the convertogenic activity of TPA in multistage skin carcinogenesis. Carcinogenesis 9:1207-1215

Picciano D (1979) Cytogenetic study of workers exposed to benzene. Environ Res 19:33-38

Popp W, Vahrenholz C, Yaman S, Müller C, Schmieding W, Norpoth K, Fahnert R (1992) Investigations of the frequency of DNA strand breakage and cross-linking and of sister chromatid exchange frequency in the lymphocytes of female workers exposed to benzene and toluene. Carcinogenesis 13:57-61

Rothman N, Haas R, Hayes RB, Li GL, Wiemels J, Campleman S, Quintana PJ, Xi LJ, Dosemeci M, Titenko-Holland N, Meyer KB, Lu W, Zhang LP, Bechtold W, Wang YZ, Kolachana P, Yin SN, Blot W, Smith MT (1995) Benzene induces gene-duplicating but not gene-inactivating mutations at the glycophorin A locus in exposed humans. Proc Natl Acad Sci USA 92:4069-4073

Rothman N, Li GL, Dosemeci M, Bechtold WE, Marti GE, Wang YZ, Linet M, Xi LJ, Lu W, Smith MT, Titenko-Holland N, Zhang LP, Blot W, Yin SN, Hayes RB (1996) Hematotoxicity among Chinese workers heavily exposed to benzene. Am J Ind Med 29:236-246

Ruiz-Ramos R, Cebrian ME, Garrido E (2005) Benzoquinone activates the ERK/MAPK signaling pathway via ROS production in HL-60 cells. Toxicology 209:279-287

Seidler A, Möhner M, Berger J, Mester B, Deeg E, Elsner G, Nieters A, Becker N (2007) Solvent exposure and malignant lymphoma: a population-based case-control study in Germany. J Occup Med Toxicol 2:2

Smith MT, Zhang L, Wang Y, Hayes RB, Li G, Wiemels J, Dosemeci M, Titenko-Holland N, Xi L, Kolachana P, Yin S, Rothman N (1998) Increased translocations and aneusomy in chromosomes 8 and 21 among workers exposed to benzene. Cancer Res 58:21762181

Smith MT, Jones RM, Smith AH (2007) Benzene exposure and risk of non-Hodgkin lymphoma. Cancer Epidemiol Biomarkers Prev 16:385-391

Snyder R (2007) Benzene's toxicity: a consolidated short review of human and animal studies by HA Khan. Hum Exp Toxicol
26:687-696. Comment on: Khan et al. (2007) Hum Exp Toxicol 26:677-685

Steffen C, Auclerc MF, Auvrignon A, Baruchel A, Kebaili K, Lambiliotte A, Leverger G, Sommelet D, Vilmer E, Hémon D, Clavel J (2004) Acute childhood leukemia and environmental exposure to potential sources of benzene and other hydrocarbons; a case-control study. Occup Environ Med 61:773-778

Subrahmanyam VV, Ross D, Eastmond DA, Smith MT (1991) Potential role of free radicals in benzene-induced myelotoxicity and leukemia. Free Radic Biol Med 11:495-515

Tompa A, Major J, Jakab MG (1994) Monitoring of benzene-exposed workers for genotoxic effects of benzene: improved-working-condition-related decrease in the frequencies of chromosomal aberrations in peripheral blood lymphocytes. Mutat Res 304:159-165

Tough IM, Smith PG, Court Brown WM, Hamden DG (1970) Chromosome studies on workers exposed to atmospheric benzene. The possible influence of age. Eur J Cancer 6:49-55

Trush MA (1984) Activation of bleomycin A2 to a DNA-damaging intermediate by phorbolester-stimulated human polymorphonuclear leukocytes. Toxicol Lett 20:297-302

Tuo J, Loft S, Poulsen HE (1999) Enhanced benzene-induced DNA damage in PMA-stimulated cells in vitro and in LPS-treated animals. Free Radic Biol Med 26:801-808

Tweats DJ, Blakey D, Heflich RH, Jacobs A, Jacobsen SD, Morita T, Nohmi T, O’Donovan MR, Sasaki YF, Sofuni T, Tice R (2007) IWGT Working Group. Report of the IWGT working group on strategy/interpretation for regulatory in vivo tests II. Identification of in vivo-only positive compounds in the bone marrow micronucleus test. Mutat Res 627:92-105

Walrand S, Valeix S, Rodriguez C, Ligot P, Chassagne J, Vasson MP (2003) Flow cytometry study of polymorphonuclear neutrophil oxidative burst: a comparison of three fluorescent probes. Clin Chim Acta 331:103-110

Winterbourn CC (2002) Biological reactivity and biomarkers of the neutrophil oxidant, hypochlorous acid. Toxicology 181182:223-227

Yager JW, Eastmond DA, Robertson ML, Paradisin WM, Smith MT (1990) Characterization of micronuclei induced in human lymphocytes by benzene metabolites. Cancer Res 50:393-399

Zarani F, Papazafiri P, Kappas A (1999) Induction of micronuclei in human lymphocytes by organic solvents in vitro. J Environ Pathol Toxicol Oncol 18:21-28

Zhang L, Wang Y, Shang N, Smith MT (1998) Benzene metabolites induce the loss and long arm deletion of chromosomes 5 and 7 in human lymphocytes. Leuk Res 22:105-113

Zhang L, Yang W, Hubbard AE, Smith MT (2005) Nonrandom aneuploidy of chromosomes $1,5,6,7,8,9,11,12$, and 21 induced by the benzene metabolites hydroquinone and benzenetriol. Environ Mol Mutagen 45:388-396 